\title{
CONSTRUCTION AND ANALYSIS OF CHINA'S INDUSTRIAL NETWORK OF CARBON CORRELATION
}

\author{
HU, W. ${ }^{1}-\mathrm{HU}, \mathrm{Y} . \mathrm{W}^{1 *}{ }^{*}-\mathrm{WANG}, \mathrm{C} . \mathrm{L}^{2}{ }^{2}-\mathrm{CHEN}, \mathrm{X} . \mathrm{Z}^{2}$ \\ ${ }^{1}$ School of Economics and Management, Shanghai University of Electric Power, Shanghai \\ 200090, China \\ ${ }^{2}$ School of Business, Shandong Normal University, Ji'nan 250014, China \\ *Corresponding author \\ e-mail:99030411@qq.com
}

(Received $7^{\text {th }}$ Jun 2019; accepted $10^{\text {th }}$ Oct 2019)

\begin{abstract}
Increasing concern about carbon emission reduction demands knowledge on the industrial structure of carbon linkages in an economy. Based on sectorial input-output analysis and network analysis, this paper develops a combined method to construct the industrial network of carbon correlation (INCC) serving as an essential tool to provide insight about carbon emission transfer and emission responsibility. Using China's 2005, 2010 and 2015 Input-Output Tables and China Energy Statistical Yearbook, China's INCCs under the transition period were constructed and the relationship structures were analyzed. Research shows that carbon emission has a decreasing trend as a whole in the transition period in China. The main consumer responsibility sectors and the critical emission transfer paths were identified to provide the analysis basis for decision makers and planners in industrial carbon management. In addition, the industry group analysis provided useful analytical techniques for carbon emission reduction policies.
\end{abstract}

Keywords: Weaver-Thomas index, carbon correlation coefficient, $\mathrm{CO}_{2}$ emission reduction, carbon transfer path, carbon cycle correlation

\section{Introduction}

Concerns over climate and environment makes the public more and more aware of the problem of greenhouse gas emissions most of which is in the form of carbon dioxide. China is currently the world's largest emitter of carbon dioxide (Lin and Sun, 2010). So the production sectors in China (including electric power production and metal smelting) became the first the focus of emission reduction. The fact that the production sectors received more attention was warranted due to the fact that these sectors account for more than half of the total carbon emissions. (Sonis et al., 1995). However, further analysis shows that carbon emissions from an industrial sector include not only direct emissions, but also indirect emissions (Chang, 2015). Some consumption sectors which have less direct emissions have a higher carbon responsibility because of their intermediate inputs, including various equipment and services. However, people pay less attention to them just because the direct emission is small (Zhang et al., 2017).

Production cannot be separated from consumption. Consumption sectors cannot be excluded to committing carbon emissions responsibilities because of their required massive intermediate inputs. As we know, industrial linkages among varied sectors can be explored by the Input-Output Table. So, Input-Output analysis is a good perspective to describe industrial linkages. Scholars (Chang and Lin, 1998; Machado et al., 2001; Labandeira and Labeaga, 2002; Jain and Gupta, 2019; Xu et al., 2019; Kaivo-oja and Luukkanen, 2004; Tahara et al., 2005; Mongelli et al., 2006; Lixon et al., 2008; Lin and Sun, 2010; Seppälä et al., 2011; Brown et al., 2012; Cadarso et al., 2012) have taken 
advantage of Input-Output of various countries or cities to track Carbon footprint. Most of their works in early discussions have found that the production sectors (such as electric power production and metal smelting) were the focus of emission reduction. Their works also established some important linkages between vary sectors, making understructure for emission responsibility and assessment in economic structures. Later, scholars gradually realized that industrial linkages would shift the responsibility of carbon emissions among the industrial sectors (Egilmez et al., 2013; Mózner, 2013; Arto et al., 2014). So we cannot explore low-carbon development in the isolated production sectors. Carbon metabolic (Baccini, 1996; Chen and Chen, 2012; Zhang et al., 2014; Wu et al., 2016; Zhang Du and Wang, 2018; Zhang et al., 2018) is then raised to investigate carbon flow and carbon transfer in social economic system. Most of these works were based on international trades and the primary target was to find the discharging countries and districts. However, carbon flows within different sub-systems or sectors were scare (Zhao et al., 2014; Zhang et al., 2018).

Carbon related responsibility can be divided into two parties, emission responsibility and requirement responsibility. In most of the study of $\mathrm{CO}_{2}$ emission problems, the direct emission factors are targeted and some main factors can be found by the Factor Decomposition Method. In view of indirect factors of carbon emissions, Structural Decomposition Method is used to study the issue of carbon emission reduction. Most of the researchers pay close attention to emission responsibility and the potential methods of reduction of high carbon emission sectors. These studies enrich the carbon emission theory and provide a reference for carbon emission reduction from the view of emission responsibility. However, existing literatures have not analyzed the main requirement responsibility of carbon emissions, this is to say, which sectors' requirement lead to the increase of emission responsibilities, and in which path industrial sectors are transmitting these responsibilities.

Network is often used to express the nodes and the relationships in group study. Analyzing network structure can excavate the deep inner structure relationships among individuals. Defining the industrial network of carbon correlation (INCC) needs to clarify all kinds of sector structures and their effects. The INCC consists of the high carbon emission sectors and some closely related consumption sectors. According to the comprehensive analysis of the INCC, we can determine which sectors are the high carbon emission sectors and which sectors are committed directly or indirectly requirement responsibilities. We can also determine which linkages are the primary transmission paths and which industrial sectors have grouped together in carbon emissions. The clarity of these problems provides the basis for adjusting policy for better developing industrial correlation structure and constructing low carbon industrial system.

This paper firstly analyzes the carbon relationships among industrial sectors, defining the concept and calculation method of industrial carbon correlation coefficient. Secondly, regarding industrial sector as node and carbon relationship as edge, this paper designs the method of constructing INCC. Thirdly, based on the Input-Output Table and the Energy Statistic Yearbook of China in 2005, 2010 and 2015, this paper constructs and analyzes the INCCs of China. Finally, through the paths and sub-graphs analysis, the main carbon emission responsibility sectors and consumption responsibility sectors are identified for industrial reduction management. 


\section{Materials and methods}

\section{Analysis of the carbon correlation between industrial sectors}

As we all know, production process often release $\mathrm{CO}_{2}$ directly by burning fossil fuels. An industrial sector requires a variety of intermediate inputs which probably emit a lot of $\mathrm{CO}_{2}$ in their production processes. Therefore, the production activities of an industrial sector often lead to other sectors emitting $\mathrm{CO}_{2}$ by intermediate demand. When sector $i$ supplies intermediate products to sector $j$, sector $i$ transfers $\mathrm{CO}_{2}$ emissions responsibility to sector $j$, and these two sectors form a carbon linkage due to industrial linkage. Similarly, sector $j$ may establish a carbon linkage with sector $k$. In this way, the industrial sectors in a region have formed carbon correlations due to industrial linkages, which lead to a network of industrial sectors, i.e., the industrial network of carbon correlation (INCC). According to INCC, the main responsible sectors for $\mathrm{CO}_{2}$ emission and the path of responsibility transmission can be identified, which provide the basis for $\mathrm{CO}_{2}$ emission reduction.

From the view of investment, the production of an industrial sector $i$ requires various intermediate inputs from multiple sectors, which emit $\mathrm{CO}_{2}$ directly in producing these inputs. All of the $\mathrm{CO}_{2}$ emitted directly by those inputs is caused by the sector $i$, so the requirement responsibility should be attributed to sector $i$. From the view of distribution, the products of sector $i$ can be divided into two parts, one part as intermediate inputs for other sectors, and the other as final product. The emission responsibility of sector $i$ should also transfer to demand sectors or final consumers with product distribution. When sector $j$ demands the product of sector $i$ which discharges $\mathrm{CO}_{2}$, it is considered that sector $i$ transfer emission responsibility to sector $j$, so there is a carbon correlation between sector $i$ and sector $j$.

In order to express the carbon correlation between industrial sectors, we define the industrial carbon correlation coefficient as: To manufacture one unit product of sector $j$ need to be directly invested in a certain number products of sector $i$, the direct $\mathrm{CO}_{2}$ emission quantity of sector $i$ in producing such products is called the carbon correlation coefficient of sector $i$ to sector $j$. The greater the coefficient, the higher is the carbon correlation strength between these two sectors. Obviously, when the amount of utilization from sector $i$ to sector $j$ increases, the industrial carbon correlation coefficient $c_{i j}$ increases. Also, when the amount of $\mathrm{CO}_{2}$ produced in one unit by sector $i$ increases, $c_{i j}$ increases, so

$$
c_{i j}=d_{i} \times a_{i j}
$$

In Equation 1, $a_{i j}$ is the direct consumption coefficient of sector $j$ from sector $i ; d_{i}$ is the $\mathrm{CO}_{2}$ amount directly discharged from sector $i$ for one unit.

We assume that $C$ is the carbon correlation coefficient matrix, $A$ represents the direct consumption coefficient matrix, and $D$ is generated by the diagonal matrix $d_{i}$. So,

$$
C=D A
$$

In Equation 1, the direct consumption coefficient $a_{i j}$ can be calculated from the Input-Output table. The emission amount per unit in production of sector $i$, i.e., $d_{i}$ can be calculated by combining the Energy Statistical Yearbook with the Input-Output Table according to the following method. 
In order to calculate $d_{i}$, it is necessary to calculate the total amount of $\mathrm{CO}_{2}$ emitting directly from this sector. Direct emission $\mathrm{CO}_{2}$ from an industrial sector occurs at the stage of burning fossil fuels, in which fossil fuels contain three primary energy sources (coal, crude oil and natural gas) and five secondary energy sources (coke, gasoline, kerosene, diesel, fuel oil). So the direct emissions of each industrial sector can be calculated according to the consumption of fossil fuels. For the non-secondary petrochemical energy conversion sector $i$, the total direct emissions $\mathrm{CO}_{2}$ from the production process are the total emissions $\mathrm{CO}_{2}$ from the consumption of various fossil fuels. Let it be $D_{i}$, then

$$
D_{i}=\sum_{s=1}^{8} u_{s}(i) \times e_{s}
$$

In the Equation 3, $u_{s}(i)$ is the total amount of energy $s$ consumed by sector $i$, and $e_{s}$ is the $\mathrm{CO}_{2}$ emission coefficient of energy $s$.

Unlike the general sector, petroleum processing, coking and nuclear fuel processing consume primary energy for obtaining secondary energy. In those productive process most of the primary energy has not changed to $\mathrm{CO}_{2}$, but has been transformed into secondary energy. However, the $\mathrm{CO}_{2}$ emissions from the secondary energy burning have already been taken into respective user sector. Therefore, in calculating the direct $\mathrm{CO}_{2}$ emission of petroleum processing, coking and nuclear fuel processing sectors, it is necessary to use Equation 1 to subtract the secondary fuels $\mathrm{CO}_{2}$ produced by them.

From the total output of each industrial sector and the total amount of $\mathrm{CO}_{2}$ emissions, we can calculate the amount $d_{i}$ of $\mathrm{CO}_{2}$ emissions per unit in sector $i$. Let the total output of sector $i$ be $X_{i}$ and the total direct $\mathrm{CO}_{2}$ emission be $D_{i}$, the unit output of sector $i$ is calculated by Equation 4:

$$
d_{i}=D_{i} / X_{i}
$$

\section{Construction of industrial network of carbon correlation}

The industrial network is a directed graph constructed by the industrial sectors and the relationships between these sectors. This graph can describe the structure of industrial sectors, revealing characteristics and laws of industrial correlation. Similarly, the INCC takes the industrial sector as the vertex and the inter-departmental carbon correlation as the edge to construct a directed graph to reveal characteristics of a given industrial carbon correlation. There are many ways to build industrial networks (Wang and Yang, 2015; Yan et al., 2017; Zhao and Yang, 2016). Here we use Weaver-Thomas index to calculate the threshold and build INCCs.

The production of an industrial sector requires different inputs from multiple sectors which vary greatly in $\mathrm{CO}_{2}$ emitting in manufacturing process. In order to find the main carbon linkages among industrial sectors, it is necessary to find the inflection point as the critical value from many carbon correlation coefficients. When the carbon correlation coefficient between the two sectors is greater than the critical value, it is considered that there exists a carbon linkage between them; otherwise there is no carbon linkage. By this way, The Weaver-Thomas index can find the key connections. So, we calculate the Weaver-Thomas index for building INCCs. 
By comparing the observed distribution with the hypothetical distribution, the best fitting approximate distribution is established to identify the key elements in the numerical sequence. For the industry including $n$ sectors, $c_{i j}$ is the carbon correlation coefficient of sector $j$ to sector $i$. If we arrange the carbon correlation coefficients $c_{1 j}, c_{2 j}$, $\ldots, c_{n j}$ from the large to the small for sector $j$, the Weaver-Thomas index of sector $i$ is:

$$
w(i, j)=\sum_{i=1}^{n}\left[s(k, i)-100 \times \frac{c_{k j}}{\sum_{l=1}^{n} c_{l j}}\right]^{2}
$$

Here, $s(k, i)=\left\{\begin{array}{c}100 / i,(k \leq i) \\ 0,(k>i)\end{array}\right.$.

Now we set, $k=\min \{w(1, j), w(2, j), \cdots, w(n, j)\}$.

So, the corresponding coefficient $c_{k j}$ of sector $j$ is the critical value of sector $k$.

By calculating the Weaver-Thomas index of each sector, we can obtain $n$ independent critical values. If the carbon correlation coefficient between two sectors is greater than the critical value, it means that here exists a carbon correlation edge, and the corresponding element in the adjacency matrix is 1 . Otherwise, it means that there is no correlation edge, and the corresponding element in the adjacency matrix is 0. Similar to the industrial network, the INCC focuses on the correlation among various sectors and not the ring in the network, so the diagonal element of the adjacency matrix is set to 0 .

\section{Analysis and expansion of INCC}

The INCC describes the carbon linkages between various industrial sectors. When there is a directed edge from sector $i$ to sector $j$ in an INCC, sector $i$ emits $\mathrm{CO}_{2}$ by providing input for sector $j$. It also can be considered that sector $i$ transfers $\mathrm{CO}_{2}$ emission responsibility to sector $j$ at the same time. This transmission make sector $j$ taking on more carbon emission requirement responsibility, as shown in Figure la. When there is no directed edge from sector $i$ to sector $j$, sector $i$ does not have $\mathrm{CO}_{2}$ emission responsibility transmitted directly to sector $j$. However, it is possible there existing a directed path in the INCC, such as, sector $i$ passes to other sectors (e.g., sector $l$, $k$, etc.), which in turn passes to sector $j$. Like this, there is an indirect carbon correlation between sector $i$ and sector $j$, as shown in Figure $1 b$.

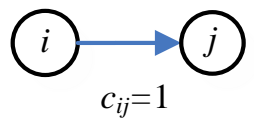

(a)

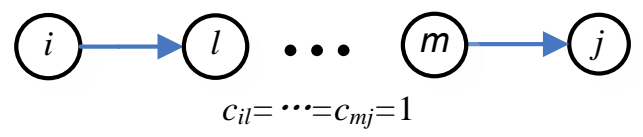

(b)

Figure 1. A directed edge and a directed path in an INCC

If all the directed edges and paths in an INCC are connected along the directed road, the extended INCC can be obtained. The degree of vertices in the extended INCC reflects the number of all other sectors linked with a sector, including direct and indirect linages. The in-degree of a sector reflects its degree of accepted requirement responsibility. When an in-degree of a sector is large, it means many sectors 
transmitting $\mathrm{CO}_{2}$ emission responsibility to this sector. It is a recipient and a major consumer responsibility sector. Out-degree reflects the degree of a sector transmitting emission responsibility. When an out-degree of a sector is large, it means that it is a main sector of emission responsibility source.

\section{China's industrial network of carbon correlations (INCCs)}

According to the Input-Output Table and the Statistical Yearbook of China in 2005, 2010 and 2015, we construct China INCCs for these three years. For facilitating comparison, the Input-Output Tables of each year and the division of sectors in the Energy Statistics Yearbook are unified, in which some industrial sectors are merged. In the Input-Output Table of 2015, "general equipment" and "professional equipment" are divided into two, while in the other two years they are unified, so we merged them. In the Input-Output Tables in 2005 and 2015, "other manufacturing" and "waste scrap" are two sectors, while in the Table of 2010 these two sectors are one, so they are merged. In the Statistical Yearbook, "transportation, warehousing and postal", "wholesale, retail and accommodation, catering" and "other industries" are combined to one into correspondence with the Input-Output Table. The correspondence between the specific industrial sector and the code is shown in Table 1.

Table 1. Industry sectors and codes after merger

\begin{tabular}{|c|c|c|c|}
\hline Code & Industrial sector & Code & Industrial sector \\
\hline 1 & $\begin{array}{c}\begin{array}{c}\text { Agriculture, forestry, animal husbandry } \\
\text { and fishery }\end{array} \\
\end{array}$ & 15 & Metal products sector \\
\hline 2 & Coal mining and washing sector & 16 & $\begin{array}{l}\text { General purpose and special equipment } \\
\text { manufacturing sector }\end{array}$ \\
\hline 3 & $\begin{array}{l}\text { Petroleum and natural gas extraction } \\
\text { sector } \\
\end{array}$ & 17 & $\begin{array}{l}\text { Transportation equipment manufacturing } \\
\text { sector }\end{array}$ \\
\hline 4 & Metal mining sector & 18 & $\begin{array}{c}\text { Electrical machinery and equipment } \\
\text { manufacturing sector }\end{array}$ \\
\hline 5 & $\begin{array}{l}\text { Nonmetallic ores and other mining and } \\
\text { mineral processing sectors }\end{array}$ & 19 & $\begin{array}{c}\text { Communications equipment, computers and } \\
\text { other electronic equipment manufacturing } \\
\text { sector }\end{array}$ \\
\hline 6 & $\begin{array}{l}\text { Food manufacturing and tobacco } \\
\text { processing sector }\end{array}$ & 20 & $\begin{array}{l}\text { Instrumentation and cultural office machinery } \\
\text { manufacturing sector }\end{array}$ \\
\hline 7 & Textile sector & 21 & $\begin{array}{l}\text { Crafts and other manufacturing sectors } \\
\text { (including waste products) }\end{array}$ \\
\hline 8 & $\begin{array}{l}\text { Textile, clothing, shoes, hats, leather, } \\
\text { feather and its products sector }\end{array}$ & 22 & Production and supply of electricity and heat \\
\hline 9 & $\begin{array}{l}\text { Wood processing and furniture } \\
\text { manufacturing }\end{array}$ & 23 & Gas production and supply sector \\
\hline 10 & $\begin{array}{c}\text { Paper making, printing, cultural, } \\
\text { educational, sporting goods } \\
\text { manufacturing }\end{array}$ & 24 & Water production and supply \\
\hline 11 & $\begin{array}{l}\text { Petroleum processing, coking and } \\
\text { nuclear fuel processing sector }\end{array}$ & 25 & Construction business \\
\hline 12 & Chemical sector & 26 & \begin{tabular}{|l} 
Transportation, storage and post \\
\end{tabular} \\
\hline 13 & Nonmetallic mineral products industry & 27 & $\begin{array}{l}\text { Wholesale, retail, accommodation and catering } \\
\text { sectors }\end{array}$ \\
\hline 14 & $\begin{array}{l}\text { Metal smelting and calendering } \\
\text { processing sector }\end{array}$ & 28 & Other sectors \\
\hline
\end{tabular}


According to the second part of the analysis and Equations 1-4, the correlation coefficient of INCCs is calculated. According to the third part of the modeling method, we build China's INCCs and the extended INCCs.

\section{Results}

\section{Correlation coefficient analysis of INCCs}

According to Equations 1-4, the industrial carbon correlation coefficients among different sectors in China' INCCs in 2005, 2010 and 2015 are calculated. The number of correlation edges in these three years 85, 76 and 83 were found significant respectively of all the 784 linkages, which means about $10 \%(10.8 \%, 9.7 \%$ and $10.6 \%)$ of the linkages pass the critical values. The top 30 in each year are listed in Table 2.

Table 2. China's top 30 INCC coefficients in 2005, 2010 and 2015

\begin{tabular}{|c|c|c|c|c|c|c|c|c|c|}
\hline \multirow[b]{2}{*}{ Sequencing } & \multicolumn{3}{|c|}{2005 year } & \multicolumn{3}{|c|}{2010 year } & \multicolumn{3}{|c|}{2015 year } \\
\hline & $\begin{array}{c}\text { INCC } \\
\text { coefficient } c_{i j}\end{array}$ & $\begin{array}{c}\text { Sector } \\
i\end{array}$ & $\begin{array}{c}\text { Sector } \\
j\end{array}$ & $\begin{array}{c}\text { INCC } \\
\text { coefficient } c_{i j}\end{array}$ & $\begin{array}{l}\text { Sector } \\
\quad i\end{array}$ & $\begin{array}{l}\text { Sector } \\
j\end{array}$ & $\begin{array}{c}\text { INCC } \\
\text { coefficient } c_{i j}\end{array}$ & $\begin{array}{l}\text { Sector } \\
\quad i\end{array}$ & $\begin{array}{c}\text { Sector } \\
j\end{array}$ \\
\hline 1 & 3.2831 & 22 & 24 & 3.6311 & 22 & 22 & 2.9632 & 22 & 22 \\
\hline 2 & 2.0365 & 22 & 4 & 3.3776 & 3 & 11 & 1.1517 & 22 & 24 \\
\hline 3 & 1.7465 & 22 & 2 & 2.8110 & 3 & 23 & 0.7816 & 14 & 14 \\
\hline 4 & 1.6622 & 11 & 26 & 2.4814 & 22 & 24 & 0.7114 & 11 & 11 \\
\hline 5 & 1.4222 & 14 & 15 & 1.4247 & 22 & 4 & 0.6760 & 22 & 4 \\
\hline 6 & 1.3298 & 22 & 3 & 1.1869 & 11 & 26 & 0.6490 & 14 & 15 \\
\hline 7 & 1.2000 & 14 & 14 & 1.0930 & 14 & 15 & 0.6420 & 11 & 26 \\
\hline 8 & 1.1515 & 11 & 23 & 0.9280 & 22 & 5 & 0.6251 & 11 & 3 \\
\hline 9 & 1.1060 & 22 & 12 & 0.9153 & 14 & 14 & 0.6074 & 2 & 2 \\
\hline 10 & 1.0513 & 22 & 5 & 0.8369 & 14 & 18 & 0.5151 & 14 & 18 \\
\hline 11 & 1.0489 & 22 & 22 & 0.7921 & 2 & 2 & 0.4618 & 22 & 14 \\
\hline 12 & 1.0387 & 2 & 22 & 0.7603 & 2 & 22 & 0.4471 & 22 & 5 \\
\hline 13 & 0.9994 & 2 & 23 & 0.7211 & 22 & 3 & 0.4263 & 2 & 22 \\
\hline 14 & 0.9365 & 22 & 13 & 0.6692 & 14 & 16 & 0.3670 & 22 & 3 \\
\hline 15 & 0.9154 & 22 & 14 & 0.6377 & 22 & 13 & 0.3601 & 11 & 12 \\
\hline 16 & 0.8986 & 11 & 4 & 0.6137 & 22 & 15 & 0.3550 & 22 & 2 \\
\hline 17 & 0.8677 & 14 & 18 & 0.5172 & 22 & 14 & 0.3332 & 22 & 13 \\
\hline 18 & 0.8054 & 14 & 16 & 0.5137 & 13 & 25 & 0.3283 & 22 & 15 \\
\hline 19 & 0.6924 & 22 & 23 & 0.4729 & 12 & 12 & 0.3084 & 11 & 14 \\
\hline 20 & 0.6829 & 22 & 15 & 0.4627 & 22 & 12 & 0.3083 & 12 & 12 \\
\hline 21 & 0.5883 & 11 & 22 & 0.4336 & 13 & 13 & 0.3046 & 14 & 16 \\
\hline 22 & 0.5723 & 3 & 11 & 0.3993 & 14 & 25 & 0.3007 & 22 & 12 \\
\hline 23 & 0.5376 & 12 & 12 & 0.3980 & 11 & 12 & 0.2911 & 11 & 5 \\
\hline 24 & 0.5226 & 11 & 5 & 0.3931 & 11 & 11 & 0.2830 & 13 & 13 \\
\hline 25 & 0.5200 & 11 & 12 & 0.3776 & 11 & 4 & 0.2724 & 22 & 11 \\
\hline 26 & 0.4445 & 14 & 17 & 0.3496 & 22 & 2 & 0.2681 & 13 & 25 \\
\hline 27 & 0.4377 & 14 & 25 & 0.3411 & 14 & 17 & 0.2598 & 14 & 25 \\
\hline 28 & 0.4092 & 22 & 10 & 0.3178 & 2 & 13 & 0.2417 & 11 & 4 \\
\hline 29 & 0.4049 & 22 & 16 & 0.3082 & 11 & 5 & 0.2307 & 2 & 23 \\
\hline 30 & 0.4019 & 22 & 27 & 0.3052 & 22 & 9 & 0.2193 & 22 & 23 \\
\hline
\end{tabular}


We can see from Table 2, in these three years of China's transition period the correlation coefficients rise in the first and then decline. The means of carbon correlation coefficients of the top 5, 12, and 30 in also show this trend. In 2010 the coefficient is the highest, indicating that carbon emissions may reach a high peak during this period (Fig. 2). This is in line with the accelerated investment of Chinese traditional industries in this period. In 2005 the coefficient is in the second place, maybe because the quantities of various industrial outputs were not so vast. After 2010, the carbon correlation coefficients show a decreasing trend from 2010 to 2015, indicating dynamic energy conversion of economic development may be acting up. To further and more comprehensive observe this trend, the first 50 carbon correlation coefficients are represented in Figure 3.

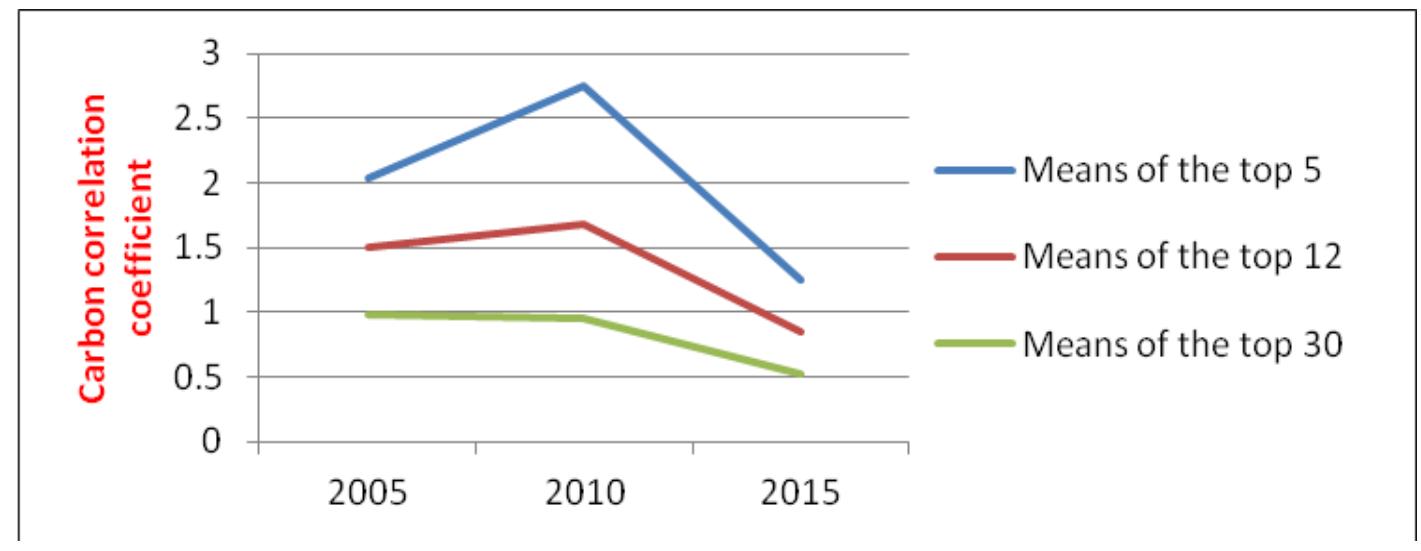

Figure 2. The means of INCC coefficients in China in 2005, 2010 and 2015

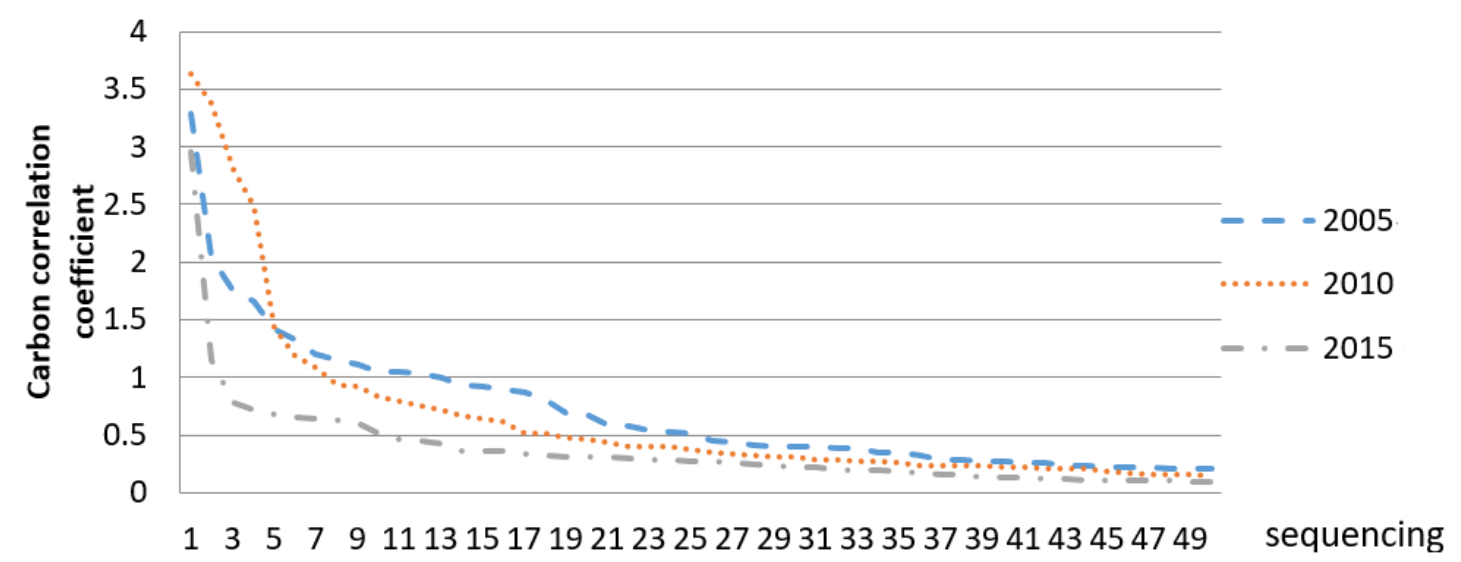

Figure 3. The top 50 INCC coefficients in China in 2005, 2010 and 2015

In each year of these transition periods, these carbon correlation coefficients show the same unbalanced state, which is the power law distribution. Among the significant coefficients which were though tested, only a few coefficients were higher, and most of them were lower. Further analysis of Table 2 and Figure 3 shows that in the first 50 carbon correlation coefficients, the main direct emission sector possessing the highest coefficients is the production and supply of electricity and heat (22), possessing 13, 11 and 13 edges in each year, nearly half of the highest carbon emission coefficients 
coming from this sector. The main indirect discharging sectors possessing the highest coefficients are water production and supply (24), metal mining and dressing, and electricity (4) and thermal production and supply (22), which emit a lot of carbon by using products from other sectors.

\section{Analysis of China's INCCs}

Analyzing the structural characteristics can excavate the intrinsic characteristics of carbon linkages among China's various industrial sectors. The basic statistical characteristics of China's INCCs in 2005, 2010 and 2015 are shown in Table 3. It is particularly interesting that, contrary to correlation coefficients trend, significant edge numbers decline in the first and then rise. In 2010, there were 76 linkages, less than 85 linages in 2005 and 83 linages in 2015. Why the carbon correlation coefficients becoming greater and the significant numbers becoming less happened at the same time in 2010? Further analysis shows that this was probably related to China's large-scale investment into some special industries in 2008.

Table 3. Basic characteristics of China' INCCs in 2005, 2010 and 2015

\begin{tabular}{c|c|c|c|c|c}
\hline & $\begin{array}{c}\text { Significant } \\
\text { numbers }\end{array}$ & $\begin{array}{c}\text { Self-circulation } \\
\text { sectors numbers }\end{array}$ & $\begin{array}{c}\text { Sector numbers with } \\
\text { more than 5 in-degrees }\end{array}$ & $\begin{array}{c}\text { Sector numbers } \\
\text { with 0 out-degree }\end{array}$ & $\begin{array}{c}\text { Sectors of the top } \\
\text { five out-degree }\end{array}$ \\
\hline 2005 & 85 & 9 & 3 & 16 & $22,11,12,14,13$ \\
2010 & 76 & 8 & 3 & 16 & $22,11,12,14,26$ \\
2015 & 83 & 10 & 1 & 14 & $22,11,12,14,26$ \\
\hline
\end{tabular}

We can see there were existing 9,8 and 10 sectors with self-recycling in these three years, that is, nearly one-third of the industrial sectors possess self-recycling carbon emissions. So, self-circulation problem in INCCs were prominent. We have also noticed that there were 7 sectors $(6,7,10,12,13,14,22)$ always possessing self-recycling in these three years and there were 2 sectors $(2,11)$ possessing self-recycling in these two years. So most self-recycling sectors have always kept stable. About half of the sectors $(16,16$ and 14 in these three years) having zero out-degree show that these sectors do not transmit emission responsibility to other sectors. They just accept carbon transmission to them and become carbon consumption sectors. These sectors are not "innocent". It is just because of their requirements that the carbon emission sector excludes a large amount of carbon, so they should bear the responsibility of carbon transfer. We have listed the sector numbers with more than 5 in-degrees for a special purpose. They were sector 8,9 and 21 in 2005, sector 6, 8 and 20 in 2010, and sector 20 in 2015. High in-degree means these sectors bear more responsibility of carbon transfer. And the sectors with more than 5 in-degrees changed from sector 8, 9 and 21 in 2005 to sector 6, 8 and 20 in 2010 and to sector 20 in 2015. The sectors had changed considerably during this transition period. Contrary to the sectors with more in-degrees, the sectors of the top five out-degrees had remained broadly consistent over the past ten years. Sector 22, 11, 12 and 14 maintained the top four in these three interval years, and the order remained unchanged. Only the fifth changed from sector 13 in 2005 to sector 26 in 2010 and 2015. From the perceptive of in-degree and out-degree, there were typical star nodes and strong sub-graphs in China's INCC graphs of these three years. The INCC graphs of these three years are shown in Figure 4. 


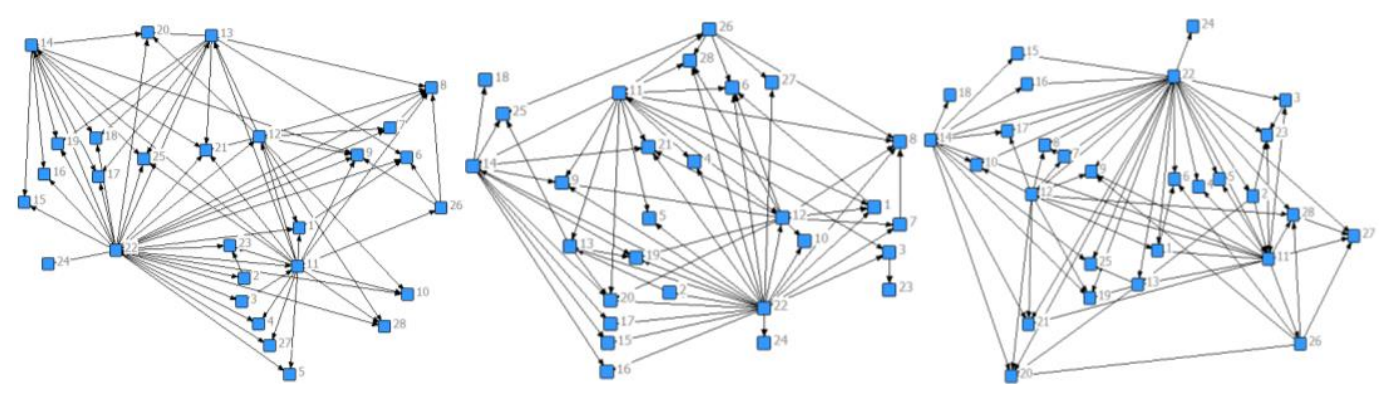

Figure 4. China's INCCs in 2005/2010/2015. (Please refer to Table 1 for the meanings of the sector numbers in the figure)

\section{Star node sector in INCC}

\section{Out-degree star topology}

As shown in Figure 4, there is a common prominent feature in these three network diagrams. Each network diagram has showed 4 or 5 star topologies, in which node sectors transmit emission responsibility to other sectors, as presented in Figure 4. According to the number of out-degree, the same top four sectors, namely, power, thermal production and supply (22), petroleum processing, coking and nuclear fuel processing (11), chemical sector (12) and metallurgical smelting and calendaring (14), have constructed a sub-network with maximum out-degree of 27 and minimum outdegree of 10 in these three years. The non-metallic mineral products sector (13) ranked fifth in 2005, with an out-degree of 9, falling to 4 in 2010 and 2015. At the same time, transportation, storage and postal service (26) increased from 3 in 2005 to 5 in 2010 and 2015. It can be seen that these sectors were the main emission sectors and that they pass the emission responsibility to other sectors through industrial linkages. Figure 5 showed the carbon emission sub-graphs of electricity and thermal production and supply (22) in these three years. Almost all connections to 22 passed the significant test.

It is of great significance to study the sub-network which constructed by the emission sectors and their consumption sectors. As the cores of these sub-networks, these sectors act as responsibility transfer source and have immediately responsibility for carbon emission. For these sub-networks, the most important thing is controlling key nodes. Although the utilization efficiency of fossil fuels, such as in electricity and thermal production and supply, is an old problem, it is also a common problem. Research and development of common technologies for carbon emission reduction is the management emphasis of out-degree star topology.

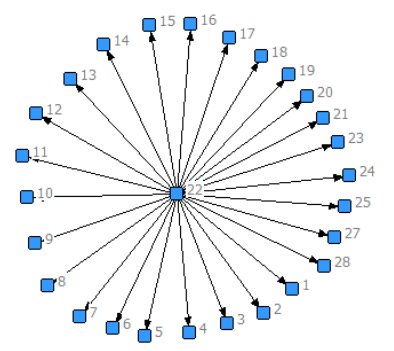

(a) 2005

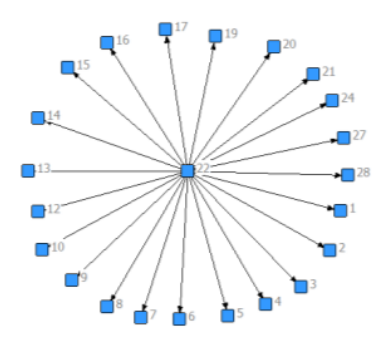

(b) 2010

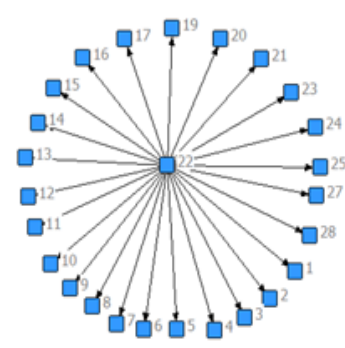

(c) 2015

Figure 5. Carbon emission sub-graphs of electricity and thermal production and supply (22). (Please refer to Table 1 for the meanings of the sector numbers in the figure) 


\section{In-degree star topology}

Different from the out-degree star topology, the in-degree star topology have smaller degrees, the maximum in-degree being 6 , and a few sectors being 4, 5 or 6 . Since the beginning of the 21st century, China's economic growth mode has changed from extensive to intensive, and the focus of economic development has gradually shifted from textile manufacturing, food manufacturing to machinery manufacturing. The development of key industries requires many other sectors' products, resulting in Changes in the in-degree star node sector. The largest in-degree sectors in 2005, 2010 and 2015 were respectively Textile, clothing, shoes, hats, leather, feather and its products industry (8), Food manufacturing and tobacco processing industry (6) and Instrumentation and cultural office machinery manufacturing industry (20), as shown in Figure 6. These sectors do not necessarily emit a lot of carbon in the process of producing their own products. However, these sectors have to bear indirect carbon responsibility because they receive products from other sectors that emit a lot of carbon in manufacturing process. Careful analysis of these three sectors in Figure 6 shows that these three highest in-degree sectors all receive carbon emissions from electricity, thermal production and supply sectors (22), chemical sector (12) and transportation, warehousing and postal services (26).

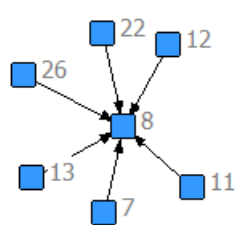

(a) sector 8 in 2005

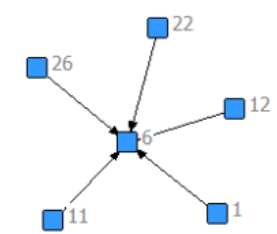

(b) sector 6 in 2010

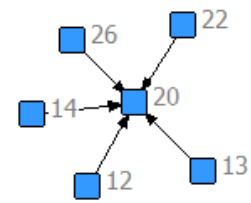

(c) sector 20 in 2015

Figure 6. Carbon emissions graphs of the in-degree star node sector. (Please refer to Table 1 for the meanings of the sector numbers in the figure)

The research about in-degree star topology is a meaningful job that few scholars have done before. First of all, we can identify the main demand responsibility sectors, which define the transfer destination of carbon emissions from the demand side. From the perspective of the social responsibility system, the complete responsibility system of carbon emissions needs perfecting analysis from both demand side and supply side. Secondly, study about in-degree star topology lays the foundation for the construction of carbon supply chain network. Carbon emissions from the demand side and the supply side can constitute a complete chain network. Thirdly, from the perspective of management regulation, In the formulation of industrial policies on carbon emissions, besides strengthening the supervision of direct carbon emission sectors, we also need to strengthen the management and control of more carbon receiving sectors.

\section{Carbon cycle correlation in INCC}

Further analysis of China's INCCs of each year reveals that there is a cyclic structure among industrial sectors. Among this cycle, the first sector provides significant carbon emissions for the second sector, while the second sector provides significant carbon emissions for the first sector directly or by other(s). Those sectors and these significant linkages form a cycle which expands the role of individual sector in carbon emissions. 
We can see from these three years, the cycles always embraced petroleum and natural gas extraction sector (3) and petroleum processing, coking and nuclear fuel processing sector (11). The difference was, these two sectors interflowed through production and supply of electricity and heat (22) in 2005, while in 2010 and 2015 these two sectors directly formed the main body of mutual carbon consumption. However, due to the sparse linkages in China's INCCs and the existence of typical star node sectors, there are not many sectors entering the circular structure, as shown in Figure 7.

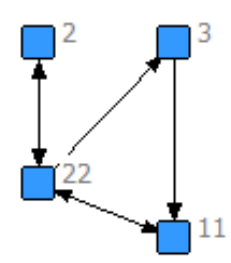

(a) In 2005

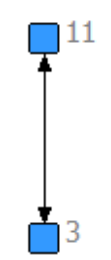

(b) In 2010 and 2015

Figure 7. Industry carbon cycle structure. (Please refer to Table 1 for the meanings of the sector numbers in the figure)

Although the structure of carbon correlation cycle among industrial sectors is rare, self-cycling exists in many sectors. There were respectively nine, eight and ten sectors with self-cycling correlations of carbon emissions in 2005, 2010 and 2015. There are seven common industrial sectors in these three years, namely, food manufacturing and tobacco processing (6), textile (7), paper making, printing, cultural, educational, sporting goods manufacturing (10), chemical (12), nonmetallic mineral products (13), metal smelting and calendering processing (14), production and supply of electricity and heat (22). It can be seen that these sectors bear significant carbon emission responsibility because of the use of products in their own sectors.

Both the circular structures and self-cycling sectors in INCC deserve great attention. Because these sectors related these bidirectional overflow structures are always establishing high carbon driving force in INCCs, including propulsive force and pulling force. Finding these micro-structures and self-circulation within and outside the sectors can help us to explore the carbon trajectory in a more subtle way. These studies also contribute to the construction of industrial balance and carbon ecosystem.

\section{Carbon emission transmission path}

The directed path in the INCCs shows the transmission path of carbon emission responsibility. In one path, the starting sector transfers the carbon emission responsibility to the intermediate sectors, while the intermediate acts as a transmitter and the terminal sector receives the responsibility from multiple sectors through multistep transmission. As shown in Figure 8, in 2005 the longest carbon transmission path consists of six steps: $2 \rightarrow 22 \rightarrow 3 \rightarrow 11 \rightarrow 12 \rightarrow 1(13) \rightarrow 6(17 \backslash 18 \backslash 19 \backslash 20 \backslash 21 \backslash 25)$. In 2010, the longest carbon transport path is five steps: $22 \rightarrow 3(2) \rightarrow 11 \rightarrow 12 \rightarrow 1(7) \rightarrow 6(8)$. In 2015, the longest carbon transmission path is also five steps, but there are two main paths: $22 \rightarrow 3(2) \rightarrow 11 \rightarrow 12(26) \rightarrow 17(28) \rightarrow 6(8 \backslash 27)$. In 2005 the carbon emission transmission paths were longer and wider than in 2010 and 2015. Sector 13 (nonmetallic mineral products) has greatly broadened the width of the path. The transmission paths in 2010 and 2015 are similar, but the transmission paths in 2015 are more complex, adding some new branches and connections. 


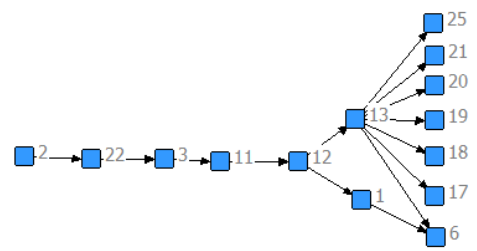

(a) In 2005

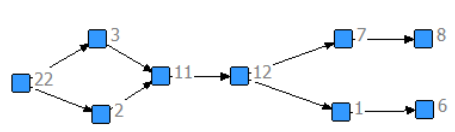

(b) In 2010

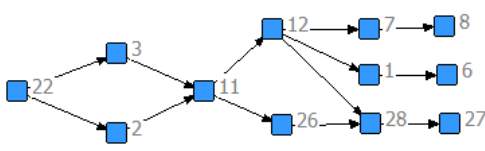

(c) In 2015

Figure 8. Carbon emission transmission path. (Please refer to Table 1 for the meanings of the sector numbers in the figure)

Path study not only emphasizes the source and destination of carbon emissions, but also emphasizes the role of "bridge" and "intermediary". Some sectors, such as sector 3 (Petroleum and natural gas extraction sector), sector 11(petroleum processing, coking and nuclear fuel processing sector) and sector 12(chemical), undertakes a strong channel role. They digest and absorb products that contain large amounts of carbon emissions, and transfer products that emit large amounts of carbon to other sectors.

\section{Analysis of extended INCC}

According to previous defining, we can also build three extended INCCs diagrams for these three years, as shown in Figure 9. As we know, in these extended INCCs, all the directed edges and paths are connected along the directed road. Directed edges are connected between two nodes with paths in the extended INCC graph. That is to say, if only there is a carbon transmission responsibility between two sectors, there is a linkage. Therefore, the significance of node degree in the extended INCC graph is more obvious. The degree of a vertice in the extended INCC reflects the number of all other sectors linked with the sector, including direct and indirect linages. So the degree of a sector in the extended INCC can be more comprehensively demonstrated the carbon linkages.

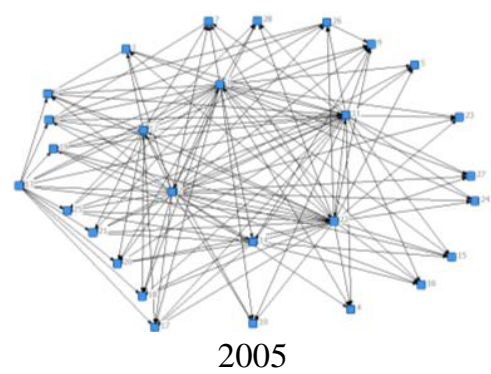

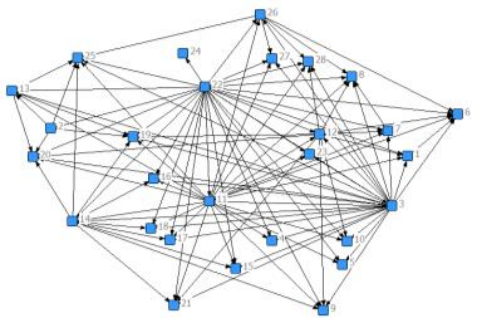

2010

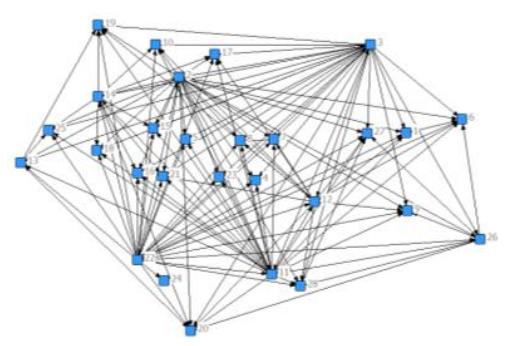

2015

Figure 9. China's extended INCC in $20052010 \backslash 2015$ (Please refer to Table 1 for the meanings of the sector numbers in the figure)

Out-degree in the extended INCCs reflects the overall emission responsibility of a sector transmitting to others. When an out-degree of a sector is large, it means that it is a main sector of emission responsibility source. As shown in Figure 9 in the extended INCC in 2005, there were four sectors (2, 3, 11 and 22) which possess 28 out-degrees, which can transmit carbon emission responsibilities to all other sectors. In the extended INCCs in 2010 and 2015, there were four sectors possessing more than 25-outdegree 
(sector 2, 3, 11 having 25, sector 22 having 27), which can transmit carbon emission responsibility to almost all other sectors. We contrast the extended INCCs and the customary INCCs, discovering sector 2 and 3 is the hidden emission source.

The in-degree in the extended INCCs reflects its overall accepted requirement responsibility of a sector. When an in-degree of a sector is large, it means many sectors transmitting $\mathrm{CO}_{2}$ emission responsibility by varied paths to this sector. It is a recipient and a major consumer responsibility sector. In all industrial sectors of three years, the largest in-degree was 7. these sectors are food manufacturing and tobacco processing (6), textile, clothing, shoes, hats, leather, feather and its products (8), wood processing and furniture manufacturing (9), communications equipment, computers and other electronic equipment manufacturing (19) and instrumentation and cultural office machinery manufacturing industry (20). It can be seen that these sectors accept carbon emission responsibilities directly or indirectly from 7 sectors. We contrast the large indegree sectors in the extended INCCs and the customary INCCs, finding that little change is found and the carbon consumption sectors sustain stable.

\section{Discussion}

Based on Weaver-Thomas index, we combine sectorial input-output analysis and network analysis to construct the industrial network of carbon correlation (INCC) for carbon emission management. We also use the data of China's 2005, 2010 and 2015 to analysis the developmental trajectories of transition period. The contribution of this paper lies in the following.

On the theoretical side, we apply network analysis to the carbon correlation study, and the carbon flow laws among industrial sectors are sorted out as a whole. Carbon correlations have formed transmission responsibilities of carbon emission between industrial sectors. We use Industrial Carbon Correlation Coefficient to describe the amount of carbon directly emitted by an industry sector in producing a unit product for another sector. The greater the coefficient, the stronger is the carbon correlation between these two sectors. Base on Industrial Carbon Correlation Coefficient, we construct INCC which is a directed graph among various industrial sectors, to describe the transmission structure of carbon emission responsibilities among industrial sectors. Constructing a national or regional INCC and analyzing the structural characteristics of the network can excavate the characteristics of carbon emissions among these national or regional industrial sectors, thus providing an analytical basis for emission reduction and other decisions.

On the practical side, we use the INCCs to find that there are typical significantly characteristics in China's INCC graphs of this transition period. First, in recent years, the carbon correlation coefficient of the same ranking has become smaller, in which 2015 is almost half of 2005. It can be seen that with the development of societies, emission reduction has been gained more effective. Secondly, these three years' INCCs indicate that there are relatively sparse significant carbon correlations between sectors and there are obvious star nodes in the INCC graphs. Star nodes are divided into outdegree type and in-degree type. As for the out-degree node, we can see that these sectors are relatively unified, and that the most prominent is the power and thermal production and supply sectors which transmit emission responsibility to almost all other sectors. Most of transmissions are direct, while some are indirect. The following sectors are petroleum processing, coking and nuclear fuel processing (11), chemical (12) and 
metal smelting and calendering (14). As for in-degree node type, more than half of all industrial sectors are in-degree nodes which only accept emissions responsibility from other sectors. The maximum in-degree sectors are food manufacturing and tobacco processing (6), textile, clothing, shoes, hats, leather, feather and its products (8), and instrumentation and cultural office machinery manufacturing sector (20). Third, there are only a few correlation cycles among transmission responsibility which involve fewer sectors in INCCs. We can see that there is only but always a cycle in the three INCCs between petroleum and natural gas extraction sector (3) and petroleum processing, coking and nuclear fuel processing sector (11). Fourth, the path in these INCCs are not very long, only 5-6 steps. There is a stable carbon emission path in the three INCCs. That is, the production and supply of electricity and heat (22) $\rightarrow$ oil and natural gas extraction (3) $\rightarrow$ oil processing, coking and nuclear fuel processing (11) $\rightarrow$ chemical (12) $\rightarrow$ agriculture, forestry, animal husbandry and fishery (1) $\rightarrow$ food manufacturing and tobacco processing (6).

The EU's carbon trading system is a leader in the global carbon trading market, and in January 2005, the EU officially launched the Greenhouse Gas Emissions Trading System (EUETS), it is the world's first greenhouse gas emissions quota trading market, using the "total limit and trading" rule. New Zealand and Australia are actively promoting the carbon trading market, New Zealand introduced mandatory carbon trading in 2008 in a step-by-step approach, Australia is one of the first countries in the world to implement mandatory greenhouse gas reduction programmes, and on July 1, 2012, Australia began implementing carbon trading nationwide.

\section{Conclusions}

In order to reduce greenhouse gas emissions such as $\mathrm{CO}_{2}$, different measures should be taken for different sectors. As the research reveals, the industrial carbon correlation coefficient between sectors is not only related to the direct input between sectors, but also related to the carbon emissions per unit. For the main out-degree sectors, such as power, thermal production and supply industries, relevant measures should be taken to reduce their direct $\mathrm{CO}_{2}$ emissions, such as reducing thermal power and increasing other forms of electricity, promoting the use of geothermal, improving energy conversion rate and so on. For the main in-degree sectors, the important ways to reduce $\mathrm{CO}_{2}$ emissions are taking measures to change the proportion of their inputs, reducing the demand of high carbon emission sectors, and trying to reduce the final demand for these products. As circle can enlarge carbon emissions, changing one or two linkages in this circle can greatly reduce carbon emissions. For long transmission paths, reducing their length can cut down carbon emissions for the whole system. In overall, Discussions about correlations, key sectors and paths allow us to look deeply into the internal productive linkages within an economy with implications for $\mathrm{CO}_{2}$ emission. They provide valuable information for planners and decision makers in formulating feasible and practical industrial polices with implications for $\mathrm{CO}_{2}$ emissions.

In the future research, we should focus on how to reduce the direct carbon emission and interrupt the correlation of carbon emission between sectors, so as to achieve the goal of energy conservation and emission reduction. How to reduce carbon dioxide emissions from industrial sector units into products; How to accurately position the responsibility of carbon emission, and can give relevant solutions. 
Acknowledgements. This work is supported by the Humanities and Social Sciences Project of Chinese Ministry of Education (Grant No.: 17YJCZH062).

\section{REFERENCES}

[1] Arto, I., Rueda-Cantuche, J. M., Peters, G. P. (2014): Comparing the GTAP-MRIO and WIOD databases for carbon footprint analysis. - Economic Systems Research 26(3): 327353.

[2] Baccini, P. (1996): Understanding regional metabolism for a sustainable development of urban systems. - Environmental Science and Pollution Research 3(2): 108-111.

[3] Brown, H. L., Buettner, G. P., Canyon, V. D., Mac Crawford, J., Judd, J. (2012): Estimating the life cycle greenhouse gas emissions of Australian ambulance services. Journal of Cleaner Production 37: 135-141.

[4] Cadarso, M., Lopes, L., Gomez, N., Tobarra, M. (2012): International trade and shared responsibility by sector. An application to the Spanish economy. - Ecological Economics 83: 221-235.

[5] Chang, N. (2015): Changing industrial structure to reduce carbon dioxide emissions: A Chinese application. - Journal of Cleaner Production 103: 40-48.

[6] Chang, Y. F., Lin, S. J. (1998): Structural decomposition of industrial CO2 emission in Taiwan: an input-output approach. - Energy Policy 26(1): 5-12.

[7] Chen, S., Chen, B. (2012): Network environ perspective for urban metabolism and carbon emissions: a case study of Vienna, Austria. - Environment Sciences \& Technology 46(8): 4498-4506.

[8] Egilmez, G., Kucukvar, M., Tatari, O. (2013): Sustainability assessment of U.S. manufacturing sectors: an economic input output-based frontier approach. - Journal of Cleaner Production 53: 91e102.

[9] Jain, S., Gupta, P. (2019): Entropy generation analysis of carbon nanotubes nanofluid 3d flow along a nonlinear inclined stretching sheet through porous media. - International Journal of Heat and Technology 37(1): 131-138.

[10] Kaivo-oja, J., Luukkanen, J. (2004): The European Union balancing between CO2 reduction commitments and growth policies: decomposition analyses. - Energy Policy 32: 1511-1530.

[11] Labandeira, J., Labeaga, J. (2002): Estimation and control of Spanish energy-related CO2 emissions: an input-output approach. - Energy Policy 30(7): 597-611.

[12] Lin, B. Q., Sun, C. W. (2010): Evaluating carbon dioxide emissions in international trade of China. - Energy Policy 38(1): 613-621.

[13] Lixon, B., Thomassin, P. J., Hamaide, B. (2008): Industrial output restriction and the Kyoto Protocol: an input-output approach with application to Canada. - Ecological Economics 68(1): 249-258.

[14] Machado, G., Schaeffer, R., Worrell, E. (2001): Energy and carbon embodied in the international trade of Brazil: an input-output approach. - Ecological Economics 39: 409424.

[15] Mongelli, I., Tassielli, G., Notarnicola, B. (2006): Global warming agreements, international trade and energy/carbon embodiments: an input-output approach to the Italian case. - Energy Policy 34(1): 88-100.

[16] Mózner, V. Z. (2013): A consumption-based approach to carbon emission accounting sectoral differences and environmental benefits. - Journal of Cleaner Production 42: 8395.

[17] Seppälä, J., Mäenpää, I., Koskela, S., Mattila, T., Nissinen, A., Katajajuuri, J., Härmä, T., Korhonen, M., Saarinen, M., Virtanen, Y. (2011): An assessment of greenhouse gas emissions and material flows caused by the Finnish economy using the ENVIMAT model. - Journal of Cleaner Production 19(16): 1833-1841. 
[18] Sonis, M., Guilhoto, J. J. M., Hewings, G. J. D., Martins, E. B. (1995): Linkages, key sectors, and structural change: some new perspectives. - SSRN Electronic Journal XXXIII(3): 233-270.

[19] Tahara, K., Sagisaka, M., Ozawa, T., Yamaguchi, K., Inaba, A. (2005): Comparison of "CO2 efficiency" between company and industry. - Journal of Cleaner Production 13(13): 1301-1308.

[20] Wang, Z., Yang, J. (2015): Study on the evaluation and selection of strategic emerging industries based on the entropy right method and Weaver-Thomas model: taking the Lujiang City belt as an example. - Science and Technology Management Research 35(20): 84-89+94.

[21] Wu, J., Qi, H., Wang, R. (2016): Insight into industrial symbiosis and carbon metabolism from the evolution of iron and steel industrial network. - Journal of Cleaner Production 135: 251-262.

[22] Xu, L. J., Wang, G. Y., Liu, T. Y., Liu, N. Z., Zhang, S. C., Sun, S. Y. (2019): A new leakoff analysis approach for acid fracturing in naturally fractured carbonate gas reservoirs. - International Journal of Heat and Technology 37(1): 139-147.

[23] Yan, X. H., Gong, H., Wang, B. C., Xie, K. C. (2017): Analysis of industrial green development countermeasures in Xi'an city based on Weaver-Thomas model. Ecological Economy 33(12): 72-76+118.

[24] Zhang, B., Du, Z., Wang, Z. (2018): Carbon reduction from sustainable consumption of waste resources: an optimal model for collaboration in an industrial symbiotic network. Journal of Cleaner Production 196: 821-828.

[25] Zhang, Y., Zheng, H., Fath, B. D. (2014): Analysis of the energy metabolism of urban socioeconomic sectors and the associated carbon footprints: model development and a case study for Beijing. - Energy Policy 73: 540-551.

[26] Zhang, Y., Li, Y., Liu, G., Hao, Y. (2017): CO2 metabolic flow analysis in global trade based on ecological network analysis. - Journal of Cleaner Production 170: 34-41.

[27] Zhang, Y., Li, Y., Liu, G., Hao, Y. (2018): CO2 metabolic flow analysis in global trade based on ecological network analysis. - Journal of Cleaner Production 170: 34-41.

[28] Zhao, R., Huang, X., Zhong, T., Liu, Y., Chuai, X. W. (2014): Carbon flow of urban system and its policy implications: the case of Nanjing. - Renewable and Sustainable Energy Reviews 33: 589-601.

[29] Zhao, Y. Y., Yang, Q. S. (2016): Analysis of innovative industrial leaders in Zhongguancun - based on the Weaver-Thomas Index. - The World of Survey and Research 9: 32-37. 